heterozygous EIF2AK4 variant carriers in the cohort (1\%), suggesting a 3-fold over-representation of heterozygous EIF2AK4 variants compared to ExAC ( $p=0.005)$.

$B M P R 2$ mutation carriers presented at a younger age and with more severe pulmonary haemodynamics compared to those without identified variants in the known PAH genes. Biallelic EIF2AK4 variant carriers had a significantly reduced transfer coefficient for carbon monoxide compared to patients with $B M P R 2$ mutations or no identified variants. Heterozygous EIF2AK4 variant carriers were similar to patients with no identified variants. There were no differences between groups in functional class or walk test distances assessed longitudinally.

$B M P R 2$ and EIF2AK4 genotype did not influence the plasma metabolome.

Discussion Biallelic EIF2AK4 variants are the second most common genetic defect in patients with apparent IPAH, after BMPR2. Variants in both genes are associated with characteristic phenotypes. Additional, non-coding variants may be present in heterozygous EIF2AK4 variant carriers. These findings have important implications for the clinical and molecular classification of PAH.

\begin{tabular}{|c|c|c|c|c|c|}
\hline & $\begin{array}{l}\text { BMPR2 } \\
\text { mutation } \\
\text { carriers }\end{array}$ & $\begin{array}{l}\text { EIF2AK4 } \\
\text { biallelic } \\
\text { variant } \\
\text { carriers }\end{array}$ & $\begin{array}{l}\text { EIF2AK4 } \\
\text { heterozygous } \\
\text { variant carriers }\end{array}$ & $\begin{array}{l}\text { Patients with } \\
\text { no identified } \\
\text { variants }\end{array}$ & $p$ \\
\hline $\begin{array}{l}\text { Female } \\
(\%)\end{array}$ & 68 & 44 & 80 & 72 & 0.282 \\
\hline $\begin{array}{l}\text { Caucasian } \\
(\%)\end{array}$ & 81 & 22 & 80 & 85 & $<0.001$ \\
\hline $\begin{array}{l}\text { Age } \\
\text { (years) }\end{array}$ & $39.79 \pm 12.97$ & $30.10 \pm 9.26$ & $54.43 \pm 21.04$ & $51.30 \pm 16.57$ & $<0.001$ \\
\hline $\begin{array}{l}\text { mPAP } \\
(\mathrm{mmHg})\end{array}$ & $60.71 \pm 11.54$ & $54.11 \pm 16.29$ & $48.25 \pm 19.57$ & $52.65 \pm 13.6$ & $<0.001$ \\
\hline CO (L/min) & $3.55 \pm 1.15$ & $4.39 \pm 1.48$ & $4.25 \pm 2.17$ & $4.26 \pm 1.47$ & $<0.001$ \\
\hline $\begin{array}{l}\text { FEV1 }(\% \\
\text { pred) }\end{array}$ & $88.68 \pm 15.77$ & $92.00 \pm 13.83$ & $82.98 \pm 22.26$ & $82.36 \pm 17.93$ & 0.055 \\
\hline FEV1/FVC & $0.78 \pm 0.08$ & $0.79 \pm 0.07$ & $0.78 \pm 0.12$ & $0.74 \pm 0.10$ & 0.004 \\
\hline $\begin{array}{l}\text { KCO (\% } \\
\text { pred) }\end{array}$ & $83.54 \pm 16.86$ & $33.84 \pm 6.48$ & $60.99 \pm 41.77$ & $67.76 \pm 22.91$ & $<0.001$ \\
\hline
\end{tabular}

Phenotypic characteristics of patients with idiopathic pulmonary arterial hypertension by genotype. Data presented as mean $\pm \mathrm{sd}$ unless stated. mPAP - mean pulmonary artery pressure; CO - cardiac output; FEV1 - forced expiratory volume 1 second; FVC - forced vital capacity; KCO - transfer coefficient for carbon monoxide.

\section{S108 LOW SKELETAL MUSCLE STRENGTH AND PHYSICAL ACTIVITY ARE ASSOCIATED WITH POOR OUTCOMES IN PULMONARY ARTERIAL HYPERTENSION}

${ }^{1} \mathrm{BE}$ Garfield, ${ }^{1} \mathrm{D}$ Shao, ${ }^{2} \mathrm{~L}$ Parfitt, ${ }^{1} \mathrm{C}$ Harries, ${ }^{2} \mathrm{~L}$ Price, ${ }^{2} \mathrm{~K}$ Dimopoulos, ${ }^{3} \mathrm{Ml}$ Polkey, ${ }^{1} \mathrm{P}$ Kemp, ${ }^{1} \mathrm{SJ}$ Wort. ${ }^{1}$ Imperial College London, London, UK; ${ }^{2}$ Royal Brompton Hospital, London, UK; ${ }^{3}$ NIHR Respiratory BRU Royal Brompton and Imperial, London, UK

\subsection{6/thoraxjnl-2016-209333.114}

Introduction Skeletal muscle wasting and low physical activity are emerging as important potentially modifiable complications of pulmonary arterial hypertension (PAH). In other conditions, such as COPD and heart failure, low muscle strength and low levels of activity have been shown to be associated with poor outcomes. We aimed to define the association of muscle strength and physical activity with hospital admission rates, long term quality of life and mortality in patients with PAH.

Methods Twenty-eight patients with $\mathrm{PAH}$ had their quadriceps maximal volitional capacity (QMVC), step count, BNP and 6MWD measured. At least 1 year later, these patients' records were reviewed and data were collected on mortality, transplantation, admission to hospital and quality of life using the EMPHASIS 10 questionnaire. QMVC was normalised to BMI and 24 patients with valid step count data were included in the analysis of activity. Kaplan-Meier plots were constructed to define mortality and ROC analysis was used to demonstrate which factors most closely predicted hospital admission. Pearson correlation was used to define the associations with follow-up quality of life. Results Kaplan-Meier plots demonstrated that patients with a QMVC/BMI $<1.1$ and those with a step count $<2500$ per day were significantly more likely to die or undergo transplant than those above these cut-offs (Figure $1 \mathrm{~A}$ and $\mathrm{B}$ ). ROC analysis showed that a QMVC/BMI $<1.5$ predicted hospital admission over the follow up period with a sensitivity of $93 \%$ and a specificity of $62 \%$. It also demonstrated that QMVC was superior to the 6MWD in predicting hospital admission (AUC 0.83, $\mathrm{p}=0.003$ vs. AUC 0.73, $\mathrm{p}=0.017$ ). Finally QMVC/BMI was significantly correlated to quality of life at follow-up in this cohort (Pearson $\mathrm{r}=-0.47, \mathrm{p}=0.018$ ).

Discussion Our data suggests that, like in other chronic conditions, low muscle strength and low physical activity in PAH are associated with poor outcomes. Treatment strategies targeting the muscle and physical activity levels may improve outcomes in terms of both quality of life and mortality.
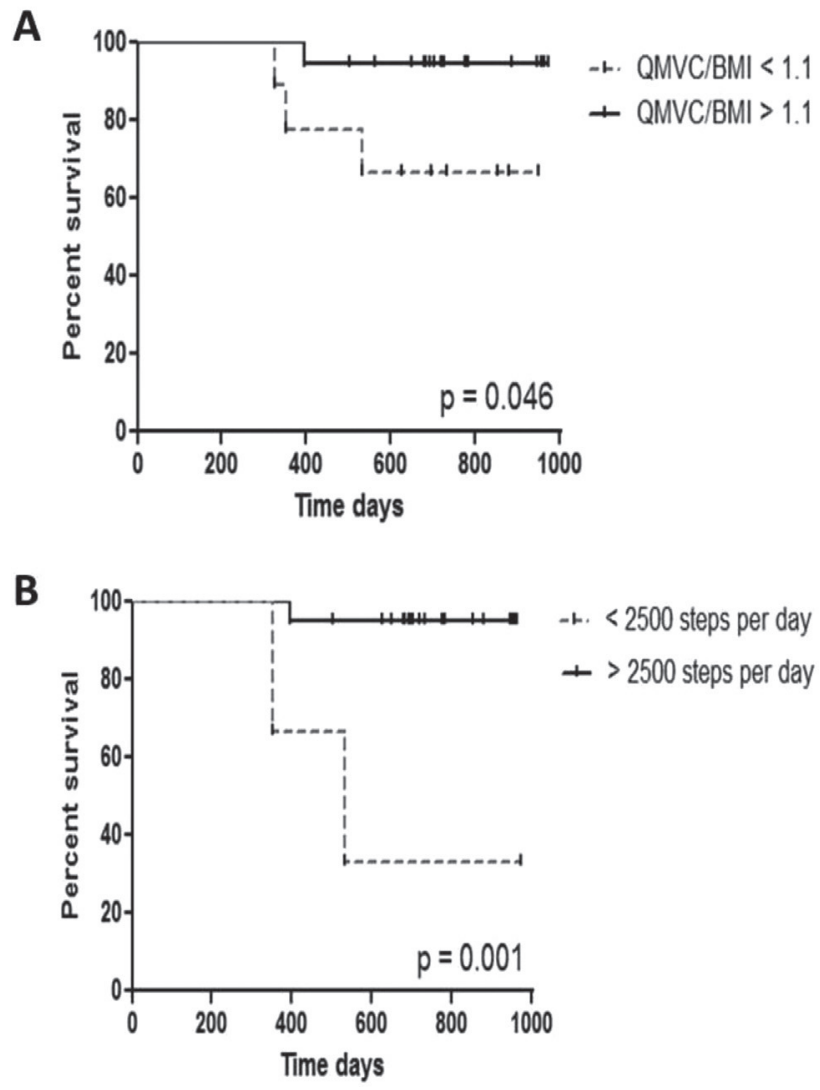

Abstract S108 Figure 1 Kaplan-Meier plots showing survival (end points being death or transplant) in patients with PAH with a: A. QMVC/BMI $<1.1$ and $>1.1$; B. step count $<2500$ and $>2500$ 